\title{
Attenuated response to methamphetamine sensitization and deficits in motor learning and memory after selective deletion of $\beta$-catenin in dopamine neurons
}

\author{
Oscar Diaz-Ruiz, ${ }^{1}$ Yajun Zhang, ${ }^{1}$ Lufei Shan, ${ }^{1}$ Nasir Malik, ${ }^{1}$ Alexander F. Hoffman, ${ }^{2}$ \\ Bruce Ladenheim, ${ }^{3}$ Jean Lud Cadet, ${ }^{3}$ Carl R. Lupica, ${ }^{2}$ Adriana Tagliaferro, ${ }^{4}$ Alicia Brusco, ${ }^{4}$ \\ and Cristina M. Bäckman ${ }^{1,5}$ \\ ${ }^{1}$ Integrative Neuroscience Section, ${ }^{2}$ Electrophysiology Research Section, ${ }^{3}$ Molecular Neuropsychiatry Section, National Institute on \\ Drug Abuse Intramural Research Program, National Institutes of Health, Baltimore, Maryland 21224, USA; ${ }^{4}$ Instituto de Biología \\ Celular y Neurociencias, UBA-CONICET, Buenos Aires 1120, Argentina
}

\begin{abstract}
In the present study, we analyzed mice with a targeted deletion of $\beta$-catenin in DA neurons (DA- $\beta$ cat KO mice) to address the functional significance of this molecule in the shaping of synaptic responses associated with motor learning and following exposure to drugs of abuse. Relative to controls, DA- $\beta$ cat $\mathrm{KO}$ mice showed significant deficits in their ability to form long-term memories and displayed reduced expression of methamphetamine-induced behavioral sensitization after subsequent challenge doses with this drug, suggesting that motor learning and drug-induced learning plasticity are altered in these mice. Morphological analyses showed no changes in the number or distribution of tyrosine hydroxylase-labeled neurons in the ventral midbrain. While electrochemical measurements in the striatum determined no changes in acute DA release and uptake, a small but significant decrease in DA release was detected in mutant animals after prolonged repetitive stimulation, suggesting a possible deficit in the DA neurotransmitter vesicle reserve pool. However, electron microscopy analyses did not reveal significant differences in the content of synaptic vesicles per terminal, and striatal DA levels were unchanged in DA- $\beta$ cat KO animals. In contrast, striatal mRNA levels for several markers known to regulate synaptic plasticity and DA neurotransmission were altered in DA- $\beta$ cat KO mice. This study demonstrates that ablation of $\beta$-catenin in DA neurons leads to alterations of motor and reward-associated memories and to adaptations of the DA neurotransmitter system and suggests that $\beta$-catenin signaling in DA neurons is required to facilitate the synaptic remodeling underlying the consolidation of long-term memories.
\end{abstract}

During brain development, growing axons learn to recognize and establish connections with the appropriate post-synaptic neurons in order to establish functional neural connections that mediate animal behavior. Once established, the synaptic circuits continue to undergo modifications such as the addition or deletion of synapses through changes in the activity of active synaptic zones. This capacity for change continues during adulthood and underlies the ability to learn and remember by encoding changes in the environment. In recent years, the intracellular signaling molecule, $\beta$-catenin has been demonstrated to play a critical role in both neural circuit formation and synaptic plasticity (Murase and Schuman 1999; Weis and Nelson 2006; Kwiatkowski et al. 2007; Maguschak and Ressler 2012). As a key component of the Wnt signaling pathway, upon activation, $\beta$-catenin translocates to the nucleus where it binds the TCF/LEF family of transcription factors to regulate the expression of Wnt targeted genes. This signaling pathway has recently been shown to be involved in the regulation of hippocampal long-term potentiation in slice preparations (Chen et al. 2006). $\beta$-catenin is also present at preand post-synaptic terminals and its association with cadherins and the actin cytoskeleton within synaptic complexes suggests direct participation in synaptic remodeling (Kwiatkowski et al. 2007). Schuman and Murase recently demonstrated that neuronal

${ }^{5}$ Corresponding author

E-mail cbackman@mail.nih.gov

Article is online at http://www.learnmem.org/cgi/doi/10.1101/lm.026716.112. depolarization causes $\beta$-catenin to move from the dendritic shafts into spines where it interacts with cadherin to influence synaptic plasticity and strength (Murase et al. 2002). $\beta$-catenin has also been shown to be important for the appropriate formation and localization of the reserve pool of synaptic vesicles at hippocampal presynaptic sites, which is necessary during sustained repetitive synaptic transmission (Bamji et al. 2003). $\beta$-catenin modulates vesicle localization in hippocampal pyramidal neurons via its ability to recruit PDZ proteins necessary to cluster synaptic vesicles around cadherin sites (Bamji et al. 2003). Thus, $\beta$-catenin seems to be an important hub molecule in synaptic plasticity, with involvement in regulating both activity-dependent synaptic remodeling and gene transcription.

Within the midbrain dopaminergic system, $\beta$-catenin has been shown to play an essential role during development, since removal of $\beta$-catenin in tyrosine hydroxylase $(\mathrm{TH})$-positive neural progenitor cells in the ventral midbrain region negatively regulates DA neuron neurogenesis. $\beta$-catenin interferes with the ability of committed progenitors to become DA neurons, resulting in adult animals with a significant decreased number of TH positive neurons in the adult ventral midbrain (Tang et al. 2009, 2010). In the present study, we determined whether $\beta$-catenin also acts beyond development in the adult dopaminergic system, to function as a signaling molecule. To examine whether $\beta$-catenin is required to maintain the integrity of synaptic transmission in DA neurons of the ventral midbrain, we studied mice with a loss-of-function mutation in the $\beta$-catenin gene specific 
to DA neurons. When examining the effects of this neuron-specific deletion, we found that $\beta$-catenin within DA neurons modulates DA neurotransmission and is required in the processes of learning and psychomotor stimulant sensitization and that postsynaptic striatal neurons respond to the lack of $\beta$-catenin in DA axon terminals by adapting mRNA expression levels of several molecular markers involved in synaptic plasticity. These findings suggest that the loss of $\beta$-catenin in DA neurons causes pre- and post-synaptic neuronal changes that may be of relevance for learning and addiction susceptibility.

\section{Results}

Conditional ablation of the $\beta$-catenin gene in the ventral mesencephalon of DA- $\beta$ cat $\mathrm{KO}$ mice is restricted to DAT-positive neurons

To investigate the role of $\beta$-catenin in the development, maintenance, and function of the dopaminergic system, we used Cre/ loxP technology to specifically ablate the $\beta$-catenin gene in postmitotic mouse DA neurons. We previously developed a "knockin" mouse that utilizes the endogenous DAT gene to promote Cre expression in DA neurons (Bäckman et al. 2006). By crossing this line with a LacZ reporter strain carrying the reporter cassette in the Rosa 26 locus (Soriano 1999), we determined that Cre recombinase activity was sufficiently robust to mediate genomic recombination and restricted to dopaminergic neurons, as $\beta$-galactosidase expression was detectable in the ventral mesencephalon soon after DAT expression at E15 (Bäckman et al. 2006), and virtually all DAT-expressing cells colocalized with $\beta$-galacosidase-stained neurons in the SN and VTA (Bäckman et al. 2006). In this study, to further demonstrate the specificity of Cre-mediated recombination at the Ctnnb1 gene locus in our DA- $\beta$ cat $\mathrm{KO}$ animals, we examined recombination in different organs using PCR primers specific to the recombined DNA (Fig. 1). PCR analyses showed Cre mediated recombination in the ventral tegmental (VTA), substantia nigra (SN), and olfactory bulb. All other areas analyzed did not show the recombination event (Fig. 1A). In addition, to determine if the Ctnnb1 deletion was specific to DATexpressing neurons within the ventral mesencephalon, we collected DAT immunoreactive (DAT + ) neurons from coronal fixed cryosections from the ventral midbrain region using UV-laser mi-
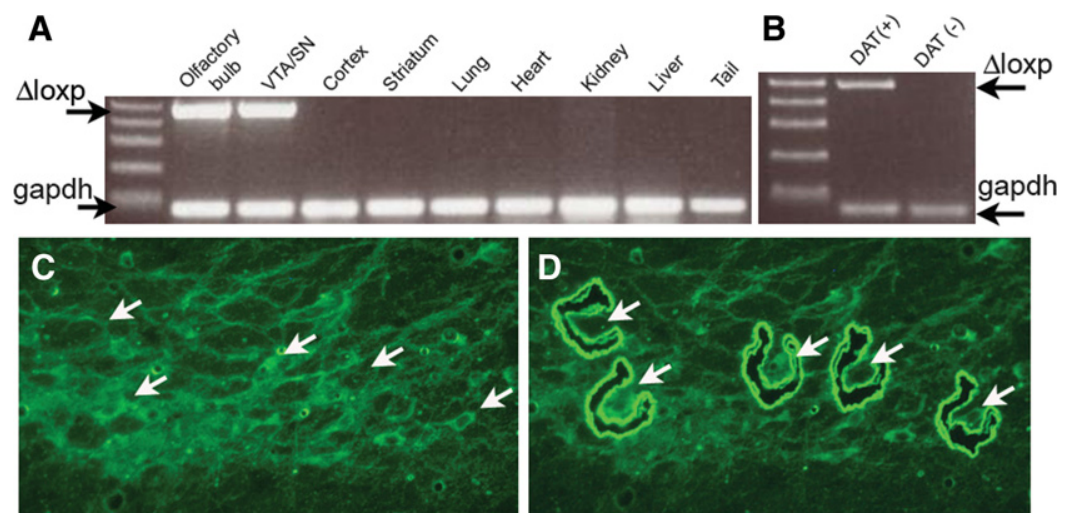

Figure 1. Cre recombinase deletes Ctnnb1 exons 1-6 in neurons expressing the dopamine transporter. (A) Genomic DNAs were prepared from the indicated tissues from a DA- $\beta$ cat KO adult mouse. PCR analyses show Ctnnb1 deletion ( $\Delta$ loxp) is specific to the olfactory bulb and SN/VTA. Ctnnb1 deletion was not detected in other tissues analyzed. $(B)$ DAT $(+)$ cells and DAT $(-)$ tissue from DA- $\beta$ cat KO animals were collected with a microdissecting microscope. The recombination band could only be detected in samples containing DAT $(+)$ neurons, indicating that Cre recombinase expression within the SN/VTA is specific to DAT $(+)$ neurons. $(C, D)$ Photomicrographs showing capturing of DAT $(+)$ cells (arrows) and DAT (-) surrounding tissue (arrowheads) for PCR processing. crodissection (Fig. 1C,D). Selected pools of 10-20 labeled DAT+ neurons and nonimmunoreactive (DAT -) SN neurons were coland analyzed by PCR. All samples containing DAT immunoreactive neurons $(\mathrm{DAT}+)$ expressed the recombination band indicating Cre mediated recombination and gene ablation at the Ctnnb1 gene locus ( $n=6$ ) (Fig. 1B). In contrast, nonimmunoreactive tissue did not show the recombination band $(n=6)$ (Fig. 1B). $\beta$-catenin recombines specifically in DAT-positive neurons within the ventral midbrain.

\section{Conditional ablation of the $\beta$-catenin gene in DA neurons} does not affect patterning of the ventral midbrain

Previous studies have shown that $\beta$-catenin regulates multiple steps during the development of DA neurons. $\beta$-catenin is required to maintain the $\mathrm{N}$-cadherin protein complex in adherent junctions and the cell polarity of progenitors in the neurogenic Th-IRES-Cre/ $\beta$-catenin KO mice negatively regulates neurogeneinterfering with the progression of committed progenitor to DA neurons (Tang et al. 2009). These results suggest $\beta$-catenin is indispensable for DA neurogenesis during the early stages of depected Mendelian ratio. However, adult KO male mice weighed (ess than age-matched WT mice (WT $=30.0 \pm 0.4$ vs. $26.2 \pm 0.4$; Student's $t$-test, $P<0.001)$. Interestingly, deletion of $\beta$-catenin in post-mitotic DA neurons, specifically around and survival of DA neurons. Thus, the number, size, and distribuDA- $\beta$ cat KO mice did not differ from WT animals (Fig. 2).

\section{$\beta$-catenin ablation in DA neurons attenuates the expression of methamphetamine-induced sensitization}

In addition to its role in development and cell proliferation, $\beta$-catenin has been implicated in neuronal synapse regulation remodeling by acting both pre- and post-synaptically (Kwiatkowski et al. 2007). For example, previous studies have shown that genetic deletion of the gene that encodes $\beta$-catenin, Ctnnb1, in the amygdala results in impaired learning by disrupting the consolidation of memories induced by fear (Maguschak and Ressler 2008). As growing evidence suggests that the behavioral sensitization induced by psychostimulants may be accompanied by long-lasting neuronal plasticity, we explored if ablation of $\beta$-catenin in DA neurons may affect the development of drug-induced behavioral changes. Interestingly, while development of sensitization to methamphetamine is unaffected in DA- $\beta$ cat $\mathrm{KO}$ mice, we observed a reduction in the sensitized response following a challenge methamphetamine injection at 7 and $30 \mathrm{~d}$ in DA- $\beta$ cat KO mice (Fig. 3A). To explore whether the failure to maintain sensitization observed in DA- $\beta$ cat $\mathrm{KO}$ mice was due to baseline locomotor impairment, we measured baseline locomotion for both WT $(n=16)$ and $\mathrm{KO}(n=$ 16) animals during a 24 -h period. The cumulative 24-h locomotor activity did not differ between the groups, and both WT and mutant animals showed a similar pattern of activity in a single day-night 

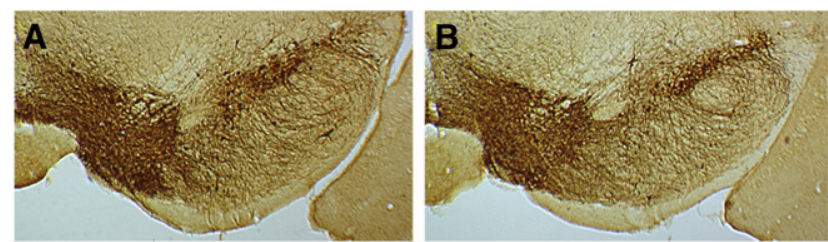

C

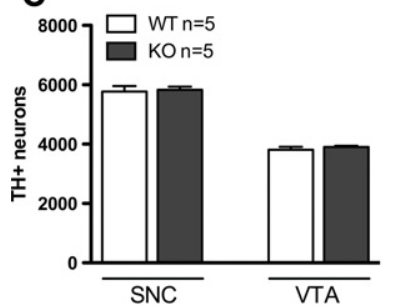

D

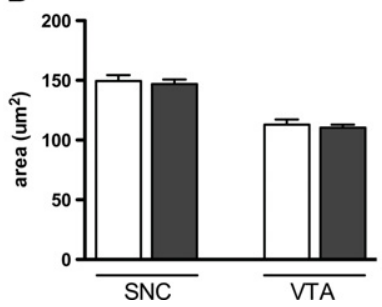

Figure 2. Immunocytochemistry for TH in the ventral midbrain of adult WT $(A)$ and DA- $\beta$ cat KO mice $(B)$. To determine the effect of $\beta$-catenin ablation in DA neurons, we compared the number of TH-positive cells and regional organization of the ventral midbrain region of adult animals. No differences were found in the morphological appearance of the ventral midbrain in adult WT and KO animals. (C) The mean number of TH-positive profiles was similar in DA- $\beta$ cat KO and WT animals. (D) The size of DA neurons in the substantia nigra compacta (SNC) and ventral tegmental area (VTA) did not change in KO mice when compared to WT animals. Student's $t$-test; $P>0.05$.

cycle (Fig. 3B). These results suggest that $\beta$-catenin is implicated in the maintenance or expression of behavioral sensitization to methamphetamine.

\section{Impaired acquisition of locomotor learning in DA- $\beta$ cat KO mice}

To investigate if the acquisition of behavioral tasks other than those associated with exposure to drugs of abuse are also affected in DA- $\beta$ cat KO mice, we measured performance acquisition on the accelerating rotarod to assay motor learning (Luft and Buitrago 2005; Yin et al. 2009). Improvement in performance across training days, as measured by increasing latency to fall from the rotarod, indicates motor learning. We used a protocol in which a 7-d rest period is interposed after a 3-d training period. This permits the measurement of both acquisition of locomotor learning and its retention. DA- $\beta$ cat $\mathrm{KO}$ mice spent significantly less time on the rotarod on all training days (Fig. 4) compared to WT animals, suggesting an overall impairment in the acquisition of this locomotor test. While DA- $\beta$ cat KO mice were able to improve their performance on the rotarod within the same day of training, suggesting that they have an ability to learn the task, a significant regression in performance was observed between days of training. The regression in performance was more pronounced upon retesting after a 7-d rest period, where the KO group latencies were comparable to the initial training session (Fig. 4). DA- $\beta$ cat KO mice were similarly impaired in the acquisition of other locomotor tasks, such as the pole test (both on the T-turn and the T-total) when compared to WT animals, thereby supporting the findings of the accelerated rotarod test (Fig. 5). However, no significant differences were found in the hanging wire test, suggesting that grip/ muscle strength is not impaired in DA- $\beta$ cat KO mice $(n=12$, $59.58 \mathrm{sec} \pm 4.17)$ when compared to WT mice $(n=12,51.83$ sec \pm 3.35 ). In addition, as DA- $\beta$ cat KO mice weigh significantly less than WT animals, it could be argued that impairments in locomotor performance in $\mathrm{KO}$ animals may be due to differences in weight among the groups. However, extensive data from our lab have correlated increased weight in $\mathrm{c} 57 \mathrm{bl} / 6$ mice with signifi- cant impairments in the pole test and rotarod (data not shown). Therefore, the impaired performance of DA- $\beta$ cat $\mathrm{KO}$ animals in both locomotor tests is most likely not correlated to their lighter weight compared to WT animals. Collectively, these data suggest the lack of $\beta$-catenin in DA neurons prevents the consolidation of newly formed motor learning into long-term memory.

\section{Functional and morphological analyses of striatal synapses in $\beta$-catenin transgenic mice}

Previous studies have shown that $\beta$-catenin plays a role in localizing synaptic vesicles at the presynaptic zone (Bamji et al. 2003), and deletion of $\beta$-catenin in hippocampal pyramidal neurons results in a reduction in the undocked pools of synaptic vesicles and reduced synaptic responses to prolonged repetitive stimulation (Bamji et al. 2003). Therefore, we hypothesized that the behavioral deficits observed in this study could be due to alterations in DA neurotransmission. To assess this possibility, we examined the dynamics of DA release in striatal brain slices using fast-scan cyclic voltammetry (FSCV). We first compared the relationship between stimulus intensity and DA release in the dorsal striatum, using local single-pulse electrical stimulation (Fig. 6A). DA- $\beta$ cat KO mice did not show a significant difference in DA release compared to control mice, suggesting that ablation of $\beta$-catenin does not affect DA release after single-pulse stimulation of afferent axons. In addition, DA uptake was unaffected in the KO mice, as evidenced by the finding that the decay time constants of the DA signals were unchanged relative to WT controls (Fig. 6B). In order to evaluate short-term plasticity at DA synapses, we compared the recovery rate of DA signals elicited by two-pulse stimulation (Fig. 6C). No significant differences were observed, suggesting that recovery
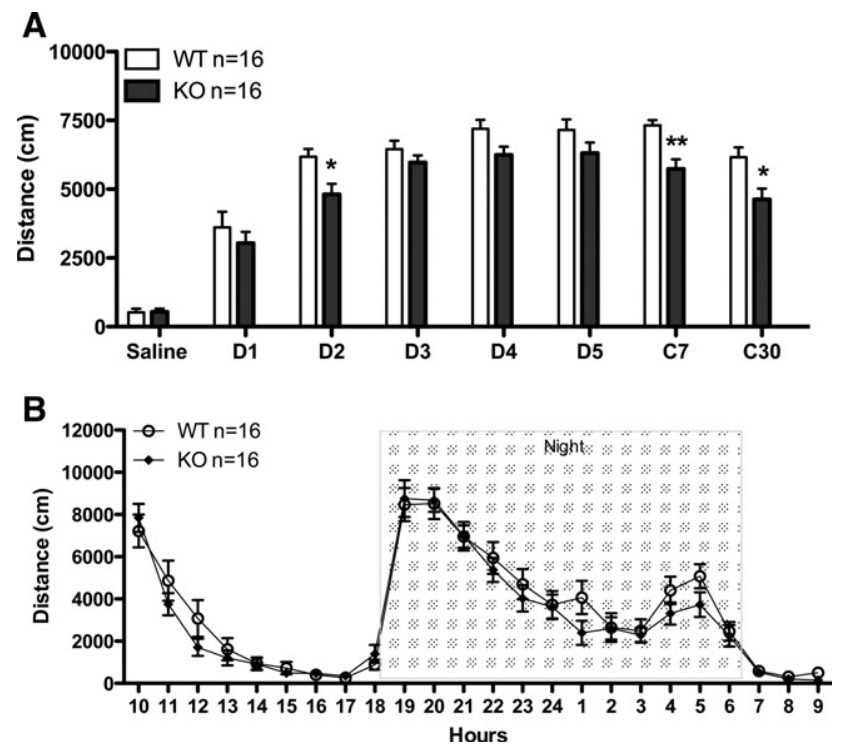

Figure 3. ( $A$ ) Methamphetamine-induced locomotor sensitization in wild-type (WT) and DA- $\beta$ cat KO mice. Cumulative 30-min locomotor response to methamphetamine in WT $(n=16)$ and KO $(n=16)$ mice at different days after injection. (Saline) Day 1 of saline injection. D1-D5 represent five consecutive days of methamphetamine injections. $\mathrm{C} 7$ and C30 represent a challenge of methamphetamine injection 7 and $30 \mathrm{~d}$ after withdrawal. Methamphetamine exposure induced significant sensitization in both WT and DA- $\beta$ cat KO mice. Induction of locomotor sensitization was less robust in $\mathrm{KO}$ animals, and maintenance of sensitization after a challenge injection was significantly reduced in DA- $\beta$ cat $\mathrm{KO}$ mice. Two-way ANOVA; (*) $P<0.05$, (**) $P<0.01$. (B) Basal locomotor activity was measured every hour for $24 \mathrm{~h}$ starting at 10:00 am. There were no significant differences between the genotypes. Two-way ANOVA; $P>0.05$. 


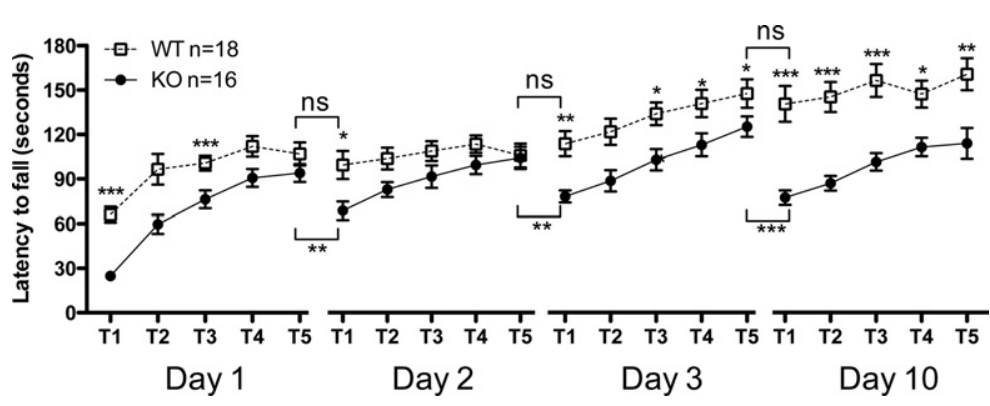

Figure 4. Locomotor learning is impaired in DA- $\beta$ cat $K O$ mice. Time spent on the rod of the accelerating rotarod for each trial completed on days 1, 2, 3, and 10. Learning retention between days of training was analyzed by pooling the average values for the last trial on each day and the first trial of the following training day. Values represent the average mean latency to fall expressed in $\sec \pm \mathrm{SEM}$. Two-way ANOVA; $\left(^{*}\right) P<0.05,\left({ }^{* *}\right) P<0.01,\left({ }^{* *}\right) P<0.001$.

times for DA release were not impaired by $\beta$-catenin deletion. However, as $\beta$-catenin has been shown to play a critical role in maintaining the reserve vesicle pool, we examined the response of $\beta$-catenin null DA synapses to prolonged repetitive stimulation. DA release was recorded during local electrical stimulation with a 10 -pulse train at a range of frequencies $(0.05-0.33 \mathrm{~Hz})$. As shown in Figure 6D, there was a frequency-dependent decline in DA release in both $\mathrm{KO}$ and WT brain slices, suggesting a greater depletion of releasable DA at higher stimulation frequencies. Furthermore, the rate of decline of the DA signal was significantly greater in DA- $\beta$ cat KO mice compared to that in WT mouse striatum. As this result may correlate with a reduction of the reserve pool of vesicles at terminal sites, we examined the morphology of synapses in the striatum of adult control and mutant mice using electron microscopy. While the overall number of synapses and vesicles per terminal in the dorsal striatum of DA- $\beta$ cat KO mice tended to be lower than that of WT animals, the data did not reach significance (Fig. 7). In addition, no significant differences in DA (WT $12,269.50 \mathrm{pg} / \mathrm{mg} \pm 432.89, n=8$ compared to $\mathrm{KO} 12,605.46 \mathrm{pg} / \mathrm{mg} \pm 522.92, n=8)$, 3,4-dihydroxyindoleacetic acid (DOPAC, WT $1194.10 \mathrm{pg} / \mathrm{mg} \pm 114.50, n=8$ compared to KO $1155.66 \mathrm{pg} / \mathrm{mg} \pm 89.97, n=8$ ), or homovanillic acid (HVA, WT $1351.87 \mathrm{pg} / \mathrm{mg} \pm 131.63, n=8$ compared to KO 1435.20 $\mathrm{pg} / \mathrm{mg} \pm 70.80, n=8)$ content was detected in the striata of $\beta$-catenin-depleted animals (ANOVA, $P>0.05$ ).

\section{Ablation of $\beta$-catenin in DA neurons leads to alterations in the expression of mRNA striatal markers}

Behavioral results suggest that ablation of $\beta$-catenin in DA neurons may alter DA neurotransmission and that learning mediated through DA neurotransmission may be permanently affected. Real-time quantitative PCR analyses were performed from striatal tissue to determine whether $\beta$-catenin ablation altered the expression of DA receptors in naive animals. D1 receptor mRNA levels were significantly down-regulated in $\mathrm{KO}$ animals compared to controls, while no significant changes were observed in mRNA levels for D2 receptors (Fig. 8). In addition, to study if the lack of $\beta$-catenin in DA neurons induces significant changes in striatal gene expression patterns in $\mathrm{KO}$ animals after induction to methamphetamine sensitization, we performed quantitative real-time PCR array analyses for a panel of 87 genes associated with synaptic plasticity (Table 1). Interestingly, $\beta$-catenin ablation in DA neurons altered the expression of a number of genes in the striatum of DA- $\beta$ cat $\mathrm{KO}$ mice after sensitization to methamphetamine. Many of these genes were related to glutamate neurotransmission, thereby suggesting that ablation of $\beta$-catenin in DA neurons could alter post-synaptic glutamate function (Table 1). In addition, Dlg4, or postsynaptic density protein 95 (PSD-95), was found to be significantly downregulated in the striatum of both naive (data not shown) and methamphetamine-treated DA- $\beta$ cat KO mice (Table 1). As PSD-95 expression is known to enhance post-synaptic clustering and activity of glutamate receptors, it is possible that changes in post-synaptic glutamate receptor expression patterns may be due to PSD-95 dysregulation.

\section{Discussion}

In this study, we have shown that deletion of $\beta$-catenin in DA neurons of the ventral midbrain leads to significant impairments in the acquisition and retention of motor learning and that it affects the expression of methamphetamine-induced behavioral sensitization. In addition, DA- $\beta$ cat KO mice demonstrated changes in striatal DA neurotransmission and in striatal markers of neuronal plasticity. Therefore, we have identified a potential role for $\beta$-catenin in DA-dependent learning and memory that is distinct from its defined role during development of the ventral mesencephalon.

Previous studies have shown that deletion of $\beta$-catenin specific to the ventral midbrain region or in DA neuron precursors leads to significant changes in the shaping of this brain region and in dopaminergic neurogenesis (Tang et al. 2009, 2010). Regional deletion of $\beta$-catenin in the ventral mesencephalon by using Shh-Cre disrupts adherent junctions of progenitors and the integrity of radial glia, which leads to a severe reduction in DA neurogenesis and perturbs the migration and segregation of DA neurons (Tang et al. 2009). In contrast, TH-IRES-Cre-mediated recombination leads to removal of $\beta$-catenin in a subset of DA neural progenitor cells and negatively regulates DA neurogenesis by interfering with the progression of committed progenitors to DA neurons, without perturbing the cellular and structural integrity of the ventral midbrain (Tang et al. 2009). These results suggest that $\beta$-catenin continues to regulate the generation of DA neurons during the process of differentiation. In this study, we have shown for the first time that deletion of $\beta$-catenin during later stages of development, in post-mitotic DA neurons $(\sim$ E15 in mice), does not mediate further morphological alterations of the patterning and survival of DA neurons in the ventral midbrain. In addition, as the post-mitotic dopaminergic system

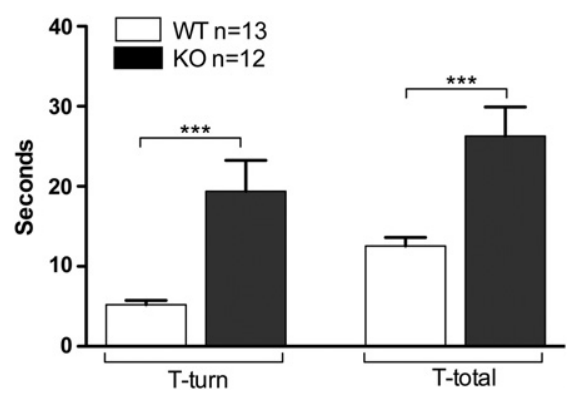

Figure 5. Pole test. Graph represents the total time it takes to turn (T-turn) and to descend the pole (T-total). Although all animals were able to perform the test, $\mathrm{KO}$ animals took significantly longer to descend the pole, indicating impaired locomotor performance. Student's $t$-test; $(* *) P<0.001$. 
A

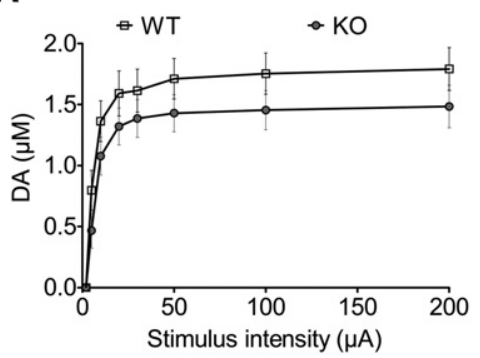

C
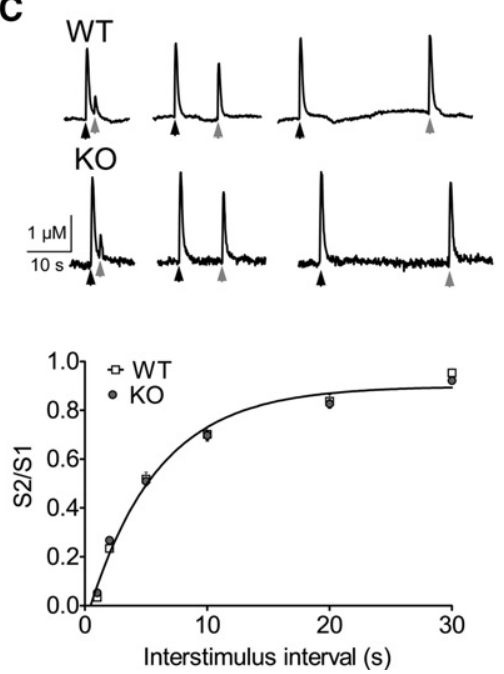

B

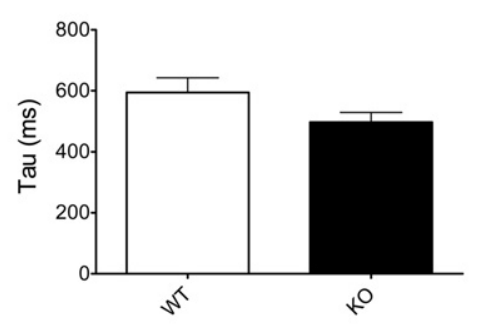

D
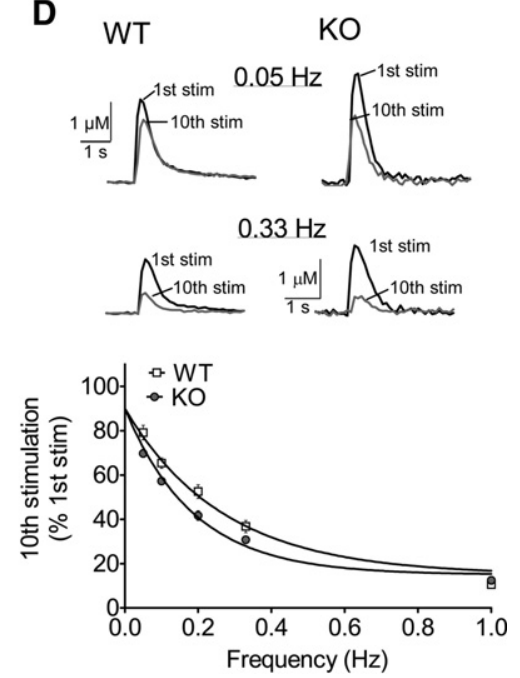

Figure 6. Assessment of dopamine release following $\beta$-catenin deletion in DA neurons. (A) Inputoutput relationship for DA release elicited by single-pulse (1-msec duration) stimulation in striatal slices from control (WT) and DA- $\beta$ cat KO mice (KO). No significant differences were observed. (B) Decay time constants of DA signals were not significantly different between control (WT) and KO mice, indicating that DA transporter-mediated uptake is not affected by gene deletion. (C) Voltammetric recording traces from a control and knockout mouse in which successive pulses ([S1] black arrow, [S2] gray arrow) were given at varying interstimulus intervals. Summary plot shows the time to recovery of the second pulse amplitude to the first pulse $(\mathrm{S} 2 / \mathrm{S} 1)$. No significant differences were observed between WT and KO mice, suggesting that recovery times for DA release were not impaired by $\beta$-catenin deletion. $(D)$ Voltammetric recording traces of the first (black) and tenth (gray) stimulation of a 10-pulse train delivered at lower $(0.05 \mathrm{~Hz})$ and higher $(0.33 \mathrm{~Hz})$ frequencies. Note the slightly greater depression of the response in the DA- $\beta$ cat KO mice. Summary plot shows the frequency-dependent decline in signal amplitude in WT and KO mice. Slices from DA- $\beta$ cat KO mice showed a significantly faster rate of decline $(\tau, 0.269 \mathrm{~Hz})$ than control mice $\left(\tau, 0.189 \mathrm{~Hz} ; F_{(1,163)}=\right.$ 25.26, $P<0.01$ ).

undergoes further pruning by apoptosis after birth (Jackson-Lewis et al. 2000), the lack of $\beta$-catenin did not affect DA neuron survival and progression of apoptosis, as the number and distribution of $\mathrm{TH}(+)$ neurons present in the SN and VTA is similar in adult WT and $\mathrm{KO}$ animals. However, recent studies suggest that regulation of $\beta$-catenin levels in adult DA neurons during injury and disease may exacerbate or protect this neuronal population from degeneration, suggesting that this protein continues to have a role in the survival of DA neurons and regulation of apoptosis during adulthood (Cajanek et al. 2009; L'Episcopo et al. 2011). Therefore, additional studies are needed to define if the lack of $\beta$-catenin during normal aging and disease may affect the survival and maintenance of the dopaminergic system.

While the effects of $\beta$-catenin regulation on the development of the dopaminergic system have been well documented, relatively little is known about the role of this molecule in adult animals. Previous studies suggest $\beta$-catenin is involved in both transcriptional regulation and stabilization of cell-cell contacts and synaptogenesis, and it is required for normal consolidation of new memories in adult mice (Maguschak and Ressler 2008, 2011, 2012). Ablation of $\beta$-catenin in neurons has been shown to affect the formation and maintenance of synapses at both presynaptic and postsynaptic sites (Murase and Schuman 1999; Murase et al. 2002; Bamji et al. 2003, 2006; Gao et al. 2007). For example, $\beta$-catenin ablation in post-synaptic sites in older cultured hippocampal pyramidal neuron cultures at a time when neurons have abundant dendritic spines results in the formation of thin, elongated spines and reduction of the amplitude of spontaneous excitatory synaptic responses (Okuda et al. 2007). Additionally, presynaptic $\beta$-catenin plays a role in the appropriate localization of the reserve pool of synaptic vesicles in hippocampal pyramidal neurons, which is necessary to maintain sustained repetitive synaptic transmission (Bamji et al. 2003; Yu and Malenka 2003; Okuda et al. 2007; Peng et al. 2009). For this reason, we measured DA release using FSCV in the dorsal striatum to investigate if the state of DA neurotransmission is altered in DA- $\beta$ cat KO mice. We found no differences in either baseline DA release or short-term plasticity at DA synapses using mild low-frequency stimulation. In contrast, and consistent with previous observations at hippocampal glutamatergic synapses, deletion of $\beta$-catenin resulted in a small but significant enhanced rate of DA depletion in response to higher frequency stimulation. These results are consistent with the idea that $\beta$-catenin may regulate the size, trafficking, and/ or distribution of the reserve vesicular DA pool. However, whereas these functional studies demonstrated impairments in DA transmission in the striata of DA- $\beta$ cat KO mice, our quantification of the number of synapses and vesicular content per synapse revealed a small but nonsignificant difference between $\mathrm{KO}$ and WT mice. However, since in this study immunolabeling was not utilized to identify DA terminals within the striatum, it is possible that a modest difference in the content of synaptic vesicles specific to DA terminals in DA- $\beta$ cat KO mice may have been masked by the overall values quantified from all synapses. Collectively, these data suggest that $\beta$-catenin deletion may only affect DA neurotransmission when high demands are placed on the system, and this may contribute to the behavioral deficits identified in this study. Alternatively, the relatively intact state of DA homeostasis observed using mild activation of this system and HPLC may indicate that DA neurotransmission may not be the sole contributor to the behavioral phenotypes observed in this study. Indeed, the changes seen in markers of glutamate function observed in DA- $\beta$ cat KO mice (below) suggest that there are downstream consequences to the loss of this protein during ontogeny.

In this study, we found that genetic deletion of Ctnnb1, the gene that encodes $\beta$-catenin, in DA neurons results in a significant 

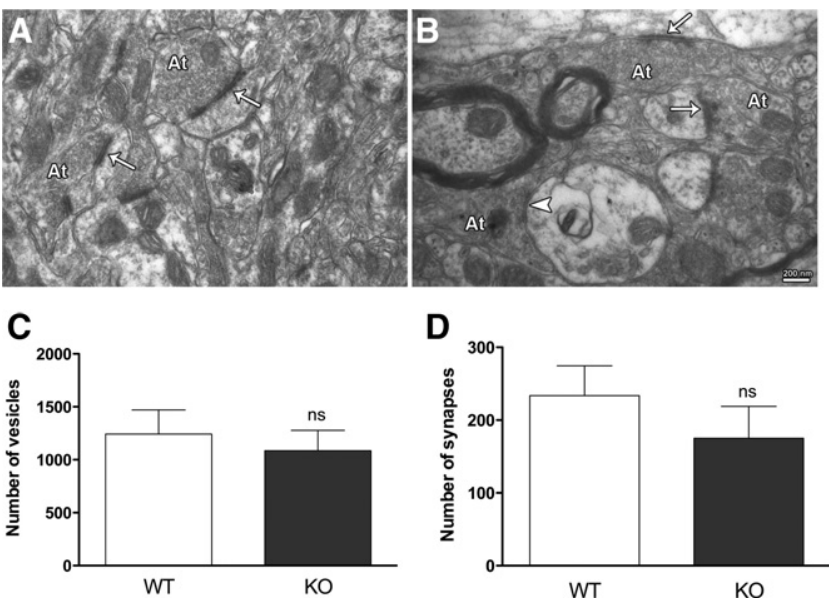

Figure 7. Electron microscopy images of synapses in the dorsal striatum of WT $(A)$ and DA- $\beta$ cat KO $(B)$ mice. Axon terminals (At) were characterized by the presence of synaptic vesicles and mitochondria. Both asymmetric synapses identified by the presence of thick post-synaptic densities (arrows) and symmetric synapses characterized by thin postsynaptic densities (arrowhead) were included in the analyses. Synapses were counted and photographed at a magnification of $12,000 \times$, and synaptic vesicles were counted and photographed at a magnification of $50,000 \times$. (C) The number of synaptic vesicles was counted in at least 100 synapses per group. Student's $t$-test; $P>0.05$. (D) An area representing $1200 \mu \mathrm{m}^{2}$ of dorsal striatum per animal was used for quantification of synapse density. Asymmetric and symmetric synapses with well-defined post-synaptic density areas were quantified. Although the KO animals exhibit a smaller number of synapses as well as a decrease in the number of synaptic vesicles, the differences between the means were not significant. Student's $t$-test; $P>0.05$.

impairment of motor skill learning and an attenuated response to methamphetamine-induced sensitization. Whereas initial sensitization to methamphetamine was not impaired in DA- $\beta$ cat KO mice, these mice showed attenuated responses to challenge injections 7 and $30 \mathrm{~d}$ following sensitization. These results are consistent with the postulated role of $\beta$-catenin in memory consolidation and synaptic stabilization (Maguschak and Ressler 2008). Extensive evidence now indicates a role for the basal ganglia, in particular, the dorsal striatum, in learning and memory. Various motor learning tasks, such as chaining of motor sequences, visuomotor skill acquisition, instrumental lever-pushing, and serial reaction-time tests all involve the striatum (Cromwell and Berridge 1996; Doyon et al. 1996; Reynolds et al. 2001; Wickens et al. 2003; Cayzac et al. 2011; Ena et al. 2011). As striatal learning is thought to depend on neuronal modification through alterations in neuronal ensemble activity and synaptic plasticity, we hypothesized that the lack of $\beta$-catenin in dopaminergic presynaptic terminals in the striatum may also alter the state of postsynaptic sites in striatal neurons. Striatal mRNA levels for DR1 were down-regulated in the striatum, while DR2 levels remained unchanged in naive mutant animals. It has previously been suggested that activation of striatal D1 receptors may contribute to the negative feedback regulation of DA release from nigrostriatal neurons (Saklayen et al. 2004). As DA availability may be decreased in DA- $\beta$ cat KO animals, down-regulation of D1R may have developed as a compensatory mechanism to facilitate DA release in the striatum of mutant animals. In addition, we examined mRNA expression levels for a panel of synaptic plasticity markers in striatal tissue after the development of sensitization to methamphetamine in WT and KO animals. Interestingly, the expression level for several ionotropic and metabotropic glutamate receptors and PSD95, a scaffolding molecule enriched at glutamatergic synapses, were altered in the striatum of DA- $\beta$ cat KO mice (Table I). Previous studies have demonstrated that post-synaptic $\beta$-catenin deletion in cultured hippocampal neurons alters homeostatic adaptations at the presynaptic site (Vitureira et al. 2011). Therefore, as it has previously been shown that the structure and function of presynaptic and post-synaptic components of the synapse are highly coordinated (Kwiatkowski et al. 2007; Vitureira et al. 2011), it is possible that expression of $\beta$-catenin at the presynaptic site, in DA axon terminals, is necessary to coordinate the formation and function of post-synaptic sites in striatal medium spiny neurons.

In summary, the results presented in this study suggest that $\beta$-catenin, a protein involved in transcriptional regulation, stabilization of cell-cell contacts, and synaptogenesis, is required for the acquisition of motor skill learning, the consolidation of longterm memories, and the strengthening of methamphetamine-induced motor sensitization in adult mice. Therefore, in addition to elucidating the involvement of $\beta$-catenin on the development and function of the DA system, this DA-specific $\beta$-catenin KO mouse model supports an existing body of work on the involvement of this protein in synaptogenesis and synaptic plasticity and supports its function in learning and memory processes as related to the activity of DA neurons.

\section{Materials and Methods}

\section{Mice}

All animal protocols were conducted under National Institutes Health (NIH) Guidelines using the NIH handbook Animals in Research and were approved by the Institutional Animal Care and Use Committee (National Institute on Drug Abuse, Intramural Research Program). Ctnnb $1^{\text {loxP }}$ mice were obtained from the Jackson Laboratory (Bar Harbor, ME) (Brault et al. 2001). For the conditional inactivation of Ctnnb1, a transgenic line, Slc6a $3^{\mathrm{Cre}}$,
A

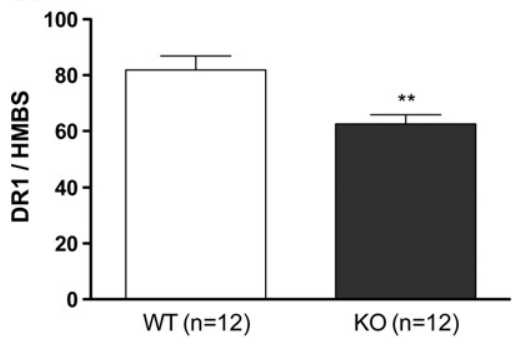

B

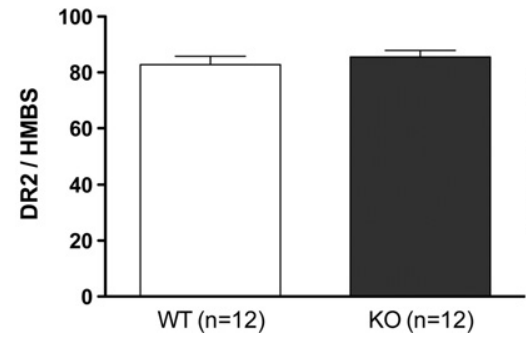

C

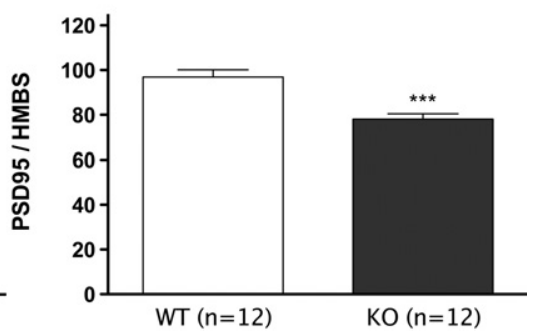

Figure 8. $\beta$-catenin ablation in DA cells affects the direct striatal output system by significantly decreasing mRNA expression levels for ( $A$ ) DR1 in striatal medium spiny neurons compared to WT animals. (B) DR2 mRNA levels were unchanged between the groups. (C) PSD95 mRNA levels were significantly decreased in DA- $\beta$ cat KO animals as compared to controls. (**) $P<0.01,\left({ }^{* * *}\right) P<0.001$; Student's $t$-test. 
Table 1. Significant dysregulation of genes related to synaptic plasticity in the striatum of DA- $\beta$ cat KO animals after a challenge injection with methamphetamine

\begin{tabular}{|c|c|c|c|c|c|c|}
\hline \multirow{2}{*}{$\frac{\text { RefSeq }}{\text { NM_177407 }}$} & \multirow{2}{*}{$\begin{array}{l}\text { Symbol } \\
\text { Camk2a }\end{array}$} & \multirow{2}{*}{$\begin{array}{c}\text { Description } \\
\text { Calcium/ } \\
\text { calmodulin-dependent } \\
\text { protein kinase II } \alpha\end{array}$} & \multicolumn{2}{|c|}{$2^{-A v g \cdot(\Delta[C t])}$} & \multirow{2}{*}{$\begin{array}{c}\begin{array}{c}\text { Fold } \\
\text { change }\end{array} \\
0.8423\end{array}$} & \multirow{2}{*}{$\begin{array}{c}P \text {-value } \\
0.003642\end{array}$} \\
\hline & & & 2.233934 & 1.881621 & & \\
\hline NM_007726 & Cnr1 & $\begin{array}{l}\text { Cannabinoid receptor } 1 \\
\text { (brain) }\end{array}$ & 0.633648 & 0.458527 & 0.7236 & 0.047764 \\
\hline NM_007864 & Dlg4 & $\begin{array}{l}\text { Discs, large homolog } 4 \\
\quad \text { (Drosophila) }\end{array}$ & 1.408932 & 1.202541 & 0.8535 & 0.044451 \\
\hline NM_010142 & Ephb2 & Eph receptor B2 & 0.003572 & 0.004777 & 1.3376 & 0.009296 \\
\hline NM_C & G & $\begin{array}{l}\text { Glutamate receptor, } \\
\text { ionotropic, AMPA4 ( } \alpha 4)\end{array}$ & 0.119827 & 0.1 & 1.1772 & 0.0 \\
\hline NM_008169 & Grin1 & $\begin{array}{l}\text { Glutamate receptor, } \\
\text { ionotropic, NMDA1 ( } \zeta \text { 1) }\end{array}$ & 0.624782 & 0.47051 & 0.7531 & 0.002607 \\
\hline NM_133442 & Grip1 & $\begin{array}{l}\text { Glutamate receptor } \\
\text { interacting protein } 1\end{array}$ & 0.01976 & 0.027277 & 1.3804 & 0.000819 \\
\hline NM_016976 & Grm1 & $\begin{array}{l}\text { Glutamate receptor, } \\
\text { metabotropic } 1\end{array}$ & 0.144961 & 0.119758 & 0.8261 & 0.0 \\
\hline NM_001160353 & Grm2 & $\begin{array}{l}\text { Glutamate receptor, } \\
\text { metabotropic } 2\end{array}$ & 0.001223 & 0.001999 & 1.6343 & 0.024463 \\
\hline NM_008689 & Nfkb1 & $\begin{array}{l}\text { Nuclear factor of } \kappa \text { light } \\
\text { polypeptide gene } \\
\text { enhancer in B-cells 1, } \\
\text { p105 }\end{array}$ & 0.015609 & 0.021075 & 1.3502 & 0.020807 \\
\hline NM_010908 & Nfkbib & $\begin{array}{l}\text { Nuclear factor of } \kappa \text { light } \\
\text { polypeptide gene } \\
\text { enhancer in B-cells } \\
\text { inhibitor, } \beta\end{array}$ & 0.003025 & 0.00359 & 1.1867 & 0.022367 \\
\hline NM_009001 & Rab3a & $\begin{array}{l}\text { RAB3A, member RAS } \\
\text { oncogene family }\end{array}$ & 1.647835 & 1.9661 & 1.1931 & 0.022564 \\
\hline NM_053075 & Rheb & $\begin{array}{l}\text { Ras homolog enriched in } \\
\text { brain }\end{array}$ & 0.183374 & 0.225547 & 1.23 & 0.025657 \\
\hline NM_019812 & Sirt1 & $\begin{array}{l}\text { Sirtuin } 1 \text { (silent mating } \\
\text { type information } \\
\text { regulation 2, homolog) } \\
1 \text { (Saccharomyces } \\
\text { cerevisiae) }\end{array}$ & 0.036387 & 0.046961 & 1.2906 & 0.019954 \\
\hline NM_020493 & Srf & Serum response factor & 0.064629 & 0.081997 & 1.2687 & 0.018233 \\
\hline
\end{tabular}

Results were normalized to housekeeping genes, and fold-change values represent the degree of changes in mRNA for KO $(n=6)$ relative to WT $(n=6)$ animals.

was used in which Cre recombinase is driven by the DA transporter promoter starting at around embryonic day 16 (Bäckman et al. 2006). To minimize interference with gene function by preservation of both alleles, Cre recombinase expression was driven from the $3^{\prime}$ untranslated region (3' UTR) of the endogenous DAT gene by means of an IRES sequence. The Ctnnb1 ${ }^{\text {loxP }}$ line was mixed with the $S l c 6 a 3^{\mathrm{Cre}}$ to obtain regional knockout (Slc6a3 ${ }^{\mathrm{Cre} /}$ ${ }^{\mathrm{wt}}$ Ctnnb $1^{\text {loxP/loxP }}$, or DA- $\beta$ cat KO) and control mice $\left(\right.$ Slc $6 a 3^{\mathrm{Cre} /}$ ${ }^{\mathrm{wt}} C t n n b 1^{w t / w t}$, or WT). Animals were genotyped using Ctnnb1 ${ }^{\text {loxP }}$ and Slc6a3 ${ }^{\text {Cre }}$ primers described elsewhere (Brault et al. 2001; Bäckman et al. 2006). To determine if Ctnnb1 deletion was specific to DAT-expressing regions, primers specific to the recombination event $(\Delta l o x P)$ were utilized (Brault et al. 2001). Dissections of the olfactory bulb, ventral mesencephalon, motor cortex, dorsal striatum, lung, heart, kidney, liver, and tail were performed, and DNA was extracted for PCR analysis. Experiments in this study were conducted in DA- $\beta$ cat $\mathrm{KO}$ and WT animals in a congenic c57bl/ 6 background.

\section{UV-laser microdissection, DNA extraction, and PCR analysis}

Coronal cryosections $(5 \mu \mathrm{m})$ of fresh frozen DA- $\beta$ cat KO mouse midbrains were cut (Leica cryostat CM3050S), mounted on polyethylene naphthalate (PEN) membrane slides (Leica Microsystems), fixed with $75 \%$ ethanol for $10 \mathrm{~min}$, acetone for $2 \mathrm{~min}$, and air-dried. Sections were incubated overnight at $4^{\circ} \mathrm{C}$ with antibodies against DAT (1:30, Chemicon) in blocking media. Sections were washed with PB and incubated for $3 \mathrm{~h}$ at RT in a mixture of secondary antibodies (Invitrogene), Alexa Flour 549 anti-rabbit IgG, made up in blocking media. Sections were washed with distilled $\mathrm{H}_{2} \mathrm{O}$, and air-dried. Fluorescent-labeled neurons were collected under epifluorescent optics using an LMD6000 system. The following types of neurons and tissue within the VTA were collected for PCR analyses: (1) DAT immunoreactive neurons ( $n=6$ samples, with $20-25$ cells per sample; (2) tissue surrounding DAT positive neurons ( $n=6$ samples). Isolated neurons and tissue were collected by gravity directly into a cap of a $0.5-\mathrm{mL}$ thin-walled PCR-tube. Cell lysis buffer (5 $\mu \mathrm{L}$ per sample) was added directly into the lid, and lysis was performed at $65^{\circ} \mathrm{C}$ for $2 \mathrm{~h}$, followed by $10 \mathrm{~min}$ at $95^{\circ} \mathrm{C}$ to inactivate proteinase $\mathrm{K}$. A multiplex reaction for the recombination band and the control gene GAPDH was performed for each sample. The recombination band $(\triangle l o x P)$ was genotyped by PCR primers: forward, 5'-CACCATGTCCTCT GTCTATTC-3' flanking the 5' loxP site, and reverse, 5'-TACACTATTGAATCAC AGGGACTT-3', and was sequenceverified. The GAPDH gene was amplified with primers: forward, $5^{\prime}$-atggtgaaggtcgg tgtga- $3^{\prime}$, and reverse, $5^{\prime}$-aatctccactttgcca ctgc- $3^{\prime}$.

\section{Immunohistochemistry}

Young adult WT and DA- $\beta$ cat KO mice were deeply anesthetized with an intraperitoneal (i.p.) injection of chloral hydrate $(30 \mathrm{mg} / \mathrm{kg})$ and perfused transcardially with saline solution followed by $4 \%$ paraformaldehyde (PFA). Brains were quickly removed from the skulls and post-fixed in $4 \%$ PFA for $4 \mathrm{~h}$. After fixation, brains were rinsed in $0.1 \mathrm{M}$ phosphate buffer $(\mathrm{PB})$ and cryoprotected in $18 \%$ sucrose solution for $48 \mathrm{~h}$ at $4^{\circ} \mathrm{C}$. Striatum and midbrain regions were cut in coronal sections at $40 \mu \mathrm{m}$ in four series using a Leica CM3050S cryostat (Leica Microsystems). Sections were incubated with rabbit polyclonal antibody against TH (1:1000, Chemicon) overnight and biotinylated anti-rabbit antibody (1:200, Vector Labs) for $1 \mathrm{~h}$. To detect signals, sections were incubated with avidinbiotinylated horseradish peroxidase for $2 \mathrm{~h}$. The peroxidase reaction was developed with $0.05 \%$ 3,3-diaminobenzidine- $4 \mathrm{HCl}$ (DAB) and $0.003 \%$ hydrogen peroxide $\left(\mathrm{H}_{2} \mathrm{O}_{2}\right)$. Sections were mounted on coated slides, coverslipped, and dried before analysis.

\section{Stereologic analyses}

Unbiased stereological counts of $\mathrm{TH}$-positive $(\mathrm{TH}+)$ neurons within the SNc and VTA were performed using stereological principles (West and Gundersen 1990) and analyzed with Stereo Investigator software (Microbrightfield). The optical fractionator probe (West et al. 1991) was used to generate an estimate of neuronal TH+ number, and the nucleator probe (Gundersen 1988) to estimate the size of TH+ neurons in SNC and VTA. The SNC and VTA were outlined under a low magnification objective $(5 x)$ following landmarks from the Franklin and Paxinos mouse atlas (Franklin and Paxinos 1997), and all the stereologic analyses were performed under the $40 \times$ objective of a Leica DM5000B microscope (Leica Microsystems). The total number of TH+ neurons and the neuronal size were measured in adult naive control and 
DA- $\beta$ cat KO mice. For each tissue section analyzed, section thickness was assessed in each sampling site; guard zones of $2.5 \mathrm{~mm}$ were set with a dissector height of $25 \mathrm{~mm}$. Systematic random sampling design was performed with a grid size of $131 \mathrm{~mm}$ and counting frame of $123 \mathrm{~mm}$. Coefficients of error were calculated and values $<0.10$ were accepted. Our criterion for counting an individual $\mathrm{TH}+$ neuron was the presence of its nucleus.

\section{Electron microscopy}

Young adult male mice were deeply anesthetized with chloral hydrate $(30 \mathrm{mg} / \mathrm{kg})$ and perfused transcardially through the left ventricle with $0.9 \%$ saline containing $1000 \mathrm{U} / \mathrm{mL}$ of heparin followed by a fixative solution containing $4 \% \mathrm{w} / \mathrm{v}$ PFA and $0.15 \% \mathrm{v} / \mathrm{v}$ glutaraldehyde in $0.1 \mathrm{M}$ phosphate buffer, $\mathrm{pH} 7.4(\mathrm{~PB})$. Brains were dissected and kept overnight in 4\% PF in PB. Vibratome coronal sections $(50 \mu \mathrm{m})$ were obtained from each brain and collected in PB. Selected sections containing rostral dorso-medial striatum were post-fixed in $1 \% \mathrm{w} / \mathrm{v}$ osmium tetroxide in $\mathrm{PB}$ for $1 \mathrm{~h}$, dehydrated through a series of graded alcohols and then with propylene oxide. Sections were flat-embedded in Durcupan ACM epoxy resin (Electron Microscopy Sciences). Ultrathin sections $(70 \mathrm{~nm})$ were cut with an ultramicrotome (Reichert-Jung Optische Werke AG). Ultrathin sections were collected onto 300-mesh cooper grids and counterstained with lead citrate (Reynolds 1963). Ultrathin sections were examined and photographed with an EM 10 Zeiss electron microscope. Brain sections from four KO and four WT mice were used for the ultra-structural study. Both asymmetric and symmetric synapses were included in this study and only synapses exhibiting a well-defined post-synaptic density were used for quantification of synapse density. The total number of synaptic vesicles was also analyzed in both asymmetric and symmetric synapses.

\section{Recordings on brain slices}

\section{Slice preparation}

Young adult mice were sacrificed by cervical dislocation, and brains were rapidly removed and placed in a modified, high-sucrose containing ice-cold artificial cerebrospinal fluid (aCSF). Coronal hemisections $(280 \mu \mathrm{m})$ containing the striatum were cut using a vibratome (Leica VT1000S). Slices were incubated in standard oxygenated aCSF at $34^{\circ}-35^{\circ} \mathrm{C}$ for $20-30 \mathrm{~min}$., then allowed to stabilize at room temperature for $>30 \mathrm{~min}$. prior to initiating recordings. During recordings, slices were continuously superfused with aCSF at a rate of $2 \mathrm{~mL} / \mathrm{min}$, and maintained at $28^{\circ}-30^{\circ} \mathrm{C}$.

\section{Voltammetric recordings}

Fast scan cyclic voltammetry was performed according to previously published protocols (Luo et al. 2010; Good et al. 2011). Carbon fibers (7- $\mu \mathrm{m}$ diameter) were vacuum-aspirated into borosilicate pipette glass. Pipettes were pulled using a conventional patch pipette puller, and the ends of the carbon fiber were cut to allow $\sim 25-30 \mu \mathrm{m}$ of exposed length protruding from the pipette tip.

Pipettes were back-filled with a $4 \mathrm{M}$ potassium acetate/ $150 \mathrm{mM} \mathrm{KCl}$ solution and connected to a standard patch pipette holder/headstage assembly. A patch clamp amplifier (HEKA EVA-8) was used to deliver voltage and measure current from the headstage. Voltammetric scan and stimulation timing protocols were performed using PCI-based A/D boards (National Instruments) and custom software (courtesy of Dr. Mark Wightman, Univ. of North Carolina). Scans consisted of sweeps from -0.4 to $1.0 \mathrm{~V}$ and back to $-0.4 \mathrm{~V}$, at a rate of $400 \mathrm{~V} / \mathrm{sec}$, and were obtained every $100 \mathrm{msec}$. A 5-sec. (50 scan) control period preceded each electrically evoked response and was used to obtain a background current that was digitally subtracted from the current obtained during the peak of the response. Currents were converted to concentration by generation of linear in vitro calibration curves for each electrode using 1-4 $\mu \mathrm{M}$ DA. All signals used in analyses matched the expected voltammetric profile for DA.

\section{Electrically evoked DA signals in brain slices}

Under stereoscopic magnification, carbon fibers were lowered to a depth of $\sim 100 \mu \mathrm{m}$ in the dorsal striatum. A bipolar stimulating electrode was positioned $\sim 75-100 \mu \mathrm{m}$ from the carbon fiber. Input-output curves (stimulus intensity vs. DA release) were constructed using single, constant current pulses $(0-250 \mu \mathrm{A}, 1-\mathrm{msec}$ duration) delivered between voltammetric scans. DA uptake was assessed by fitting the decay portion of each signal to a single exponential function. The obtained $\tau$ values are independent of the signal amplitude and have previously been demonstrated to be related to the efficiency of DAT-mediated uptake of DA $(\mathrm{Vmax} / \mathrm{Km})$ and are sensitive to DAT inhibitors (Chen et al. 2008). In order to estimate the mean recovery time for vesicular DA, a two-pulse protocol was used while varying the interpulse interval (1-30 sec). The ratio of the peak of the second pulse to the peak of the first pulse $(\mathrm{S} 2 / \mathrm{S} 1)$ was plotted as a function of the interpulse interval and fit utilizing a one-phase association $Y=\operatorname{Ymax}^{*}\left(1-\mathrm{e}^{-\mathrm{kx}}\right)$, where Ymax is the plateau and $\mathrm{Y}=0.5^{*} \mathrm{Ymax}$ when $x=0.6932$ / $\mathrm{K}$. In order to estimate the rate of vesicular depletion, a series of 10 pulses was given at varying frequencies $(0.05-1 \mathrm{~Hz})$. The amplitude of the 10th pulse was normalized to the amplitude of the first pulse and plotted against the stimulation frequency. Data were fit to a single exponential decay function $\mathrm{Y}=$ $\mathrm{Ymax}^{*} \mathrm{e}^{-\mathrm{kx}}$. All curve fits, as well as between group comparisons of curves, were performed using GraphPad Prism (v. 5.0; GraphPad Scientific).

\section{HPLC analyses of DA and metabolites}

Striatal tissues obtained from young adult mice were weighed and stored at $-80^{\circ} \mathrm{C}$ until extraction. The tissues obtained from each animal were homogenized in $0.1 \mathrm{M}$ perchloric acid and centrifuged at $25,000 \mathrm{~g}$ for $12 \mathrm{~min}$. DOPAC, DA, and HVA contents in supernatants of the brain structures were measured by HPLC with electrochemical detection. The analytical column was a SunFire C18 5 um $(4.6 \times 150.0 \mathrm{~mm})$ from Waters. The mobile phase was $0.01 \mathrm{M}$ sodium dihydrogenphosphate, $0.01 \mathrm{M}$ citric acid, $1.2 \mathrm{mM}$ sodium EDTA, $1.2 \mathrm{mM}$ sodium 1-heptane sulfonic acid, $10 \%$ methanol, $\mathrm{pH} 3.5$ at flow rate $1.0 \mathrm{~mL} / \mathrm{min}$ and column temperature $34^{\circ} \mathrm{C}$. The installation consisted of a Waters 717 Plus automated injection system, a Waters 1525 Binary pump, and an ESA Coulochem III detector. The Waters Breeze system was used for analysis. Concentrations of DOPAC, DA and HVA were calculated as $\mathrm{pg} / \mathrm{mg}$ of tissue weight. Statistical analysis was performed using analysis of variance (ANOVA) followed by Fisher's protected least significant difference (PLSD) (StatView 4.02, SAS Institute). Criteria for significance were set at $P<0.05$.

\section{Real time PCR and $\mathrm{RT}^{2}$ profiler synaptic plasticity arrays}

Striatal tissue from young adult naive WT $(n=12)$ and KO $(n=$ 12) animals was dissected and immediately processed for RNA isolation and DNAse I treatment using the RNAqueous-Micro Ambion kit (Applied Biosystems-Ambion), following the manufacturer's instructions. For cDNA synthesis, total RNA was mixed following the manufacturers instructions for the Superscript III reverse transcriptase kit (Invitrogen). Real-time polymerase chain reaction was performed as duplicate determinations with specific Taqman probes from the mouse Probe Library (Exiqon A/S) designed for primers to mouse DR1, F: $5^{\prime}$-tctggtttacctgatccctca-3', B: 5'-gcctcctcctcttcaggt-3'; DR2, F: 5'-ctctttggactcaacaacacaga3', B: 5'-aagggcacgtagaacgagac-3'; and PSD-95, F: 5'-cgctaccaagatgaa gacacg-3', B: 5'-caatcacagggggagaattg-3'. Hydroxymethylbilane synthase (Hmbs), F: 5'-tccctgaaggatgtgcctac-3', B: 5'-acaagggttt tcccgtttg-3'; and hypoxanthine guanine phosphoribosyl tra nsferase1 (Hprt1), F: 5'-tgatagatccattcctatgactgtaga-3', B: 5'-aaga cat tctttccagttaaagttgag- $3^{\prime}$, were used as housekeeping genes to normalize quantification data. The reproducibility of results was determined by inspection of duplicate samples. After an initial incubation step for $10 \mathrm{~min}$ at $95^{\circ} \mathrm{C}$, qRT-PCR was carried out using 40 cycles $\left(95^{\circ} \mathrm{C}\right.$ for $15 \mathrm{sec}, 60^{\circ} \mathrm{C}$ for $\left.60 \mathrm{sec}\right)$. The standard curve method was used to compare mRNA expression levels between $\mathrm{KO}$ and control animals. 
To determine if ablation of $\beta$-catenin in DA neurons affects the pattern of mRNA expression for synaptic plasticity markers in striatal neurons after methamphetamine treatment, PCR microarrays that interrogate 84 genes involved in synaptic plasticity were used. Striatal tissue was dissected from WT $(n=6)$ and DA- $\beta$ cat $\mathrm{KO}(n=6)$ mice $24 \mathrm{~h}$ after challenge treatment with methamphetamine on day 30 and was immediately processed for total RNA isolation and DNAse I treatment using the RNAqueous-Micro Ambion kit (Applied Biosystems-Ambion), following the manufacturers instructions. Total RNA for each individual animal was reverse-transcribed into cDNA using the RT ${ }^{2}$ First Strand Kit (SA Biosciences), mixed with $\mathrm{RT}^{2}$ qPCR mastermix containing SYBR Green (SA Biosciences), and aliquoted in equal volumes to each well of the mouse synaptic plasticity $\mathrm{RT}^{2}$ Profiler PCR Array (part no. PAMM 126, SA Biosciences). A separate $\mathrm{RT}^{2}$ Profiler Array was utilized for each individual animal. The real-time PCR cycling program was run on an HT7900 Cycler (Applied Biosystems). Data were normalized using multiple housekeeping genes and analyzed by comparing $2^{-\Delta \mathrm{Ct}}$ of the normalized samples in WT and KO animals by $\mathrm{RT}^{2}$ Profiler PCR Array data analysis software (http://pcrdataanalysis.sabiosciences.com/ pcr/arrayanalysis.php).

\section{Behavioral analyses}

\section{Basal locomotor activity}

Young adult mice were individually placed in the locomotor activity chambers $(43 \times 43 \times 30 \mathrm{~cm})$ for $24 \mathrm{~h}$, with free access to food and water. Locomotor activity was monitored with an infrared activity monitoring system and coordinated by Accuscan software. Data were stored every hour, starting at 10:00 am. Analyses of variance with Bonferroni post-hoc analysis were applied to compare means among the groups and time points. Statistical significance was set at $P<0.05$.

\section{Methamphetamine sensitization}

Young adult mice were habituated (day 0 ) to the chambers and to the injection protocol before the beginning of the experiment. On day 0 , WT and DA- $\beta$ cat KO mice were placed in the locomotor activity chambers $(42 \times 42 \times 30 \mathrm{~cm})$ for a 1 -h habituation period. Thereafter, animals received an i.p. saline injection and were placed back into the chamber for one more hour of locomotor activity. At the end of the second hour, mice received an additional i.p. saline injection, and activity was recorded for one more hour. On the next day, and for five consecutive days, all mice were placed in the Plexiglas boxes for $1 \mathrm{~h}$ for habituation; at the end of the hour, animals received a saline injection and were left for one more hour. At the end of the second hour, mice received a single methamphetamine injection (2.5 mg/kg, i.p.), and activity was recorded for one more hour. Animals received a challenge injection with methamphetamine 7 and $30 \mathrm{~d}$ following the cessation of methamphetamine treatment and following the same protocol presented above. Analyses of variance with Bonferroni post-hoc analysis were applied to compare means among the groups and days of training. Statistical significance was set at $P<0.05$.

\section{Accelerating rotarod}

The rotarod was specifically designed for making automated measurements of neurological deficits in rodents and is one of the most commonly used tests of motor function in mice (Luft and Buitrago 2005; Yin et al. 2009). In this study, motor coordination, balance, and motor learning were evaluated with the acceleratingrotarod test. A rotarod apparatus (Accuscan Instruments) with a 30-mm-diameter rod was set to accelerate from 4 to 40 revolutions per minute $(\mathrm{rpm})$ over $300 \mathrm{sec}$. Wild-type $(n=18)$ and DA- $\beta$ cat KO $(n=16)$ mice received five consecutive trials per session, one session per day for three consecutive days. Rest between trials was $30 \mathrm{sec}$. Mice were placed on the rod apparatus, and latency to fall was recorded. Seven days after the last session, mice were tested again under the same conditions. The latency of the mice to fall from the rod was scored as an index of their motor coordination. Improvement in performance across training days indi- cates motor learning, and enhanced performance at the start of the second training week is a measure of retention of locomotor learning. Analyses of variance with Bonferroni post-hoc analysis were applied to compare means among the groups and days of training. Statistical significance was set at $P<0.05$.

\section{Pole test}

Motor dysfunction was also evaluated using the pole test (Matsuura et al. 1997). The pole test consists of an $\sim 50-\mathrm{cm}-\mathrm{high}$, gauze-taped pole $(1 \mathrm{~cm}$ in diameter). The latency before the mouse turned toward the ground (T-turn) and landed (T-total) was recorded. Mice were habituated for the task in five trials per day for two consecutive days. On test day (day 3), measures were taken over five trails per mouse and the average calculated to rate performance. Data were analyzed using Student's $t$-test. Statistical significance was set at $P<0.05$.

\section{Grid test}

Young adults were lifted by the tail and gently placed in the center of a horizontal square grid with black walls $(40 \times 40 \times 15 \mathrm{~cm}$ with mesh of $0.5-\mathrm{cm}^{2}$ squares) $\sim 20 \mathrm{~cm}$ above a box with bedding. The grid was momentarily shaken to help mice grasp the mesh and then inverted, so mice were hanging upside down. The test had a duration of $2 \mathrm{~min}$. The time it took the mice to fall was recorded (Tillerson and Miller 2003). Data were analyzed using Student's $t$-test. Statistical significance was set at $P<0.05$.

\section{Acknowledgments}

This work was supported by the U.S. Department of Health and Human Services, the National Institutes of Health, and the National Institute on Drug Abuse Intramural Research Program. We thank Dr. Barry J. Hoffer for helpful comments on the manuscript.

\section{References}

Bäckman CM, Malik N, Zhang Y, Shan L, Grinberg A, Hoffer BJ, Westphal H, Tomac AC. 2006. Characterization of a mouse strain expressing Cre recombinase from the $3^{\prime}$ untranslated region of the dopamine transporter locus. Genesis 44: 383-390.

Bamji SX, Shimazu K, Kimes N, Huelsken J, Birchmeier W, Lu B, Reichardt LF. 2003. Role of $\beta$-catenin in synaptic vesicle localization and presynaptic assembly. Neuron 40: 719-731.

Bamji SX, Rico B, Kimes N, Reichardt LF. 2006. BDNF mobilizes synaptic vesicles and enhances synapse formation by disrupting cadherin- $\beta$-catenin interactions. J Cell Biol 174: 289-299.

Brault V, Moore R, Kutsch S, Ishibashi M, Rowitch DH, McMahon AP, Sommer L, Boussadia O, Kemler R. 2001. Inactivation of the $\beta$-catenin gene by Wnt1-Cre-mediated deletion results in dramatic brain malformation and failure of craniofacial development. Development 128: $1253-1264$

Cajanek L, Ribeiro D, Liste I, Parish CL, Bryja V, Arenas E. 2009. Wnt/ $\beta$-catenin signaling blockade promotes neuronal induction and dopaminergic differentiation in embryonic stem cells. Stem Cells 27: 2917-2927.

Cayzac S, Delcasso S, Paz V, Jeantet Y, Cho YH. 2011. Changes in striatal procedural memory coding correlate with learning deficits in a mouse model of Huntington disease. Proc Natl Acad Sci 108: 9280-9285.

Chen J, Park CS, Tang SJ. 2006. Activity-dependent synaptic Wnt release regulates hippocampal long term potentiation. J Biol Chem 281: 11910-11916.

Chen YH, Harvey BK, Hoffman AF, Wang Y, Chiang YH, Lupica CR. 2008. MPTP-induced deficits in striatal synaptic plasticity are prevented by glial cell line-derived neurotrophic factor expressed via an adenoassociated viral vector. FASEB J 22: 261-275.

Cromwell HC, Berridge KC. 1996. Implementation of action sequences by a neostriatal site: A lesion mapping study of grooming syntax. J Neurosci 16: $3444-3458$.

Doyon J, Owen AM, Petrides M, Sziklas V, Evans AC. 1996. Functional anatomy of visuomotor skill learning in human subjects examined with positron emission tomography. Eur J Neurosci 8: 637-648.

Ena S, de Kerchove d'Exaerde A, Schiffmann SN. 2011. Unraveling the differential functions and regulation of striatal neuron sub-populations in motor control, reward, and motivational processes. Front Behav Neurosci 5: 47. 
Franklin KBJ, Paxinos G. 1997. The mouse brain in stereotaxic coordinates. Academic Press, San Diego, CA.

Gao X, Arlotta P, Macklis JD, Chen J. 2007. Conditional knock-out of $\beta$-catenin in postnatal-born dentate gyrus granule neurons results in dendritic malformation. J Neurosci 27: 14317-14325.

Good CH, Hoffman AF, Hoffer BJ, Chefer VI, Shippenberg TS, Bäckman CM, Larsson NG, Olson L, Gellhaar S, Galter D, et al. 2011. Impaired nigrostriatal function precedes behavioral deficits in a genetic mitochondrial model of Parkinson's disease. FASEB J 25: 1333-1344.

Gundersen HJ. 1988. The nucleator. J Microsc 151: 3-21.

Jackson-Lewis V, Vila M, Djaldetti R, Guegan C, Liberatore G, Liu J, O'Malley KL, Burke RE, Przedborski S. 2000. Developmental cell death in dopaminergic neurons of the substantia nigra of mice. J Comp Neurol 424: $476-488$.

Kwiatkowski AV, Weis WI, Nelson WJ. 2007. Catenins: Playing both sides of the synapse. Curr Opin Cell Biol 19: 551-556.

L'Episcopo F, Serapide MF, Tirolo C, Testa N, Caniglia S, Morale MC, Pluchino S, Marchetti B. 2011. A Wnt1 regulated Frizzled-1/ $\beta$-Catenin signaling pathway as a candidate regulatory circuit controlling mesencephalic dopaminergic neuron-astrocyte crosstalk: Therapeutical relevance for neuron survival and neuroprotection. Mol Neurodegener 6: 49.

Luft AR, Buitrago MM. 2005. Stages of motor skill learning. Mol Neurobiol 32: $205-216$.

Luo Y, Good CH, Diaz-Ruiz O, Zhang Y, Hoffman AF, Shan L, Kuang SY, Malik N, Chefer VI, Tomac AC, et al. 2010. NMDA receptors on nondopaminergic neurons in the VTA support cocaine sensitization. PLoS One 5: e12141. doi: 10.1371/journal.pone.0012141.

Maguschak KA, Ressler KJ. 2008. $\beta$-catenin is required for memory consolidation. Nat Neurosci 11: 1319-1326.

Maguschak KA, Ressler KJ. 2011. Wnt signaling in amygdala-dependent learning and memory. I Neurosci 31: 13057-13067.

Maguschak KA, Ressler KJ. 2012. The dynamic role of $\beta$-catenin in synaptic plasticity. Neuropharmacology 62: 78-88.

Matsuura K, Kabuto H, Makino H, Ogawa N. 1997. Pole test is a useful method for evaluating the mouse movement disorder caused by striatal dopamine depletion. J Neurosci Methods 73: 45-48.

Murase S, Schuman EM. 1999. The role of cell adhesion molecules in synaptic plasticity and memory. Curr Opin Cell Biol 11: 549-553.

Murase S, Mosser E, Schuman EM. 2002. Depolarization drives $\beta$-Catenin into neuronal spines promoting changes in synaptic structure and function. Neuron 35: 91-105.

Okuda T, Yu LM, Cingolani LA, Kemler R, Goda Y. 2007. $\beta$-Catenin regulates excitatory postsynaptic strength at hippocampal synapses. Proc Natl Acad Sci 104: 13479-13484.
Peng YR, He S, Marie H, Zeng SY, Ma J, Tan ZJ, Lee SY, Malenka RC, Yu X. 2009. Coordinated changes in dendritic arborization and synaptic strength during neural circuit development. Neuron 61: 71-84.

Reynolds ES. 1963. The use of lead citrate at high $\mathrm{pH}$ as an electron-opaque stain in electron microscopy. J Cell Biol 17: 208-212.

Reynolds JN, Hyland BI, Wickens JR. 2001. A cellular mechanism of reward-related learning. Nature 413: 67-70.

Saklayen SS, Mabrouk OS, Pehek EA. 2004. Negative feedback regulation of nigrostriatal dopamine release: Mediation by striatal D1 receptors. J Pharmacol Exp Ther 311: 342-348.

Soriano P. 1999. Generalized lacZ expression with the ROSA26 Cre reporter strain. Nat Genet 21: 70-71.

Tang M, Miyamoto Y, Huang EJ. 2009. Multiple roles of $\beta$-catenin in controlling the neurogenic niche for midbrain dopamine neurons. Development 136: 2027-2038.

Tang M, Villaescusa JC, Luo SX, Guitarte C, Lei S, Miyamoto Y, Taketo MM, Arenas E, Huang EJ. 2010. Interactions of Wnt/ $\beta$-catenin signaling and sonic hedgehog regulate the neurogenesis of ventral midbrain dopamine neurons. J Neurosci 30: 9280-9291.

Tillerson JL, Miller GW. 2003. Grid performance test to measure behavioral impairment in the MPTP-treated-mouse model of Parkinsonism. I Neurosci Methods 123: $189-200$

Vitureira N, Letellier M, White IJ, Goda Y. 2011. Differential control of presynaptic efficacy by postsynaptic N-cadherin and $\beta$-catenin. Nat Neurosci 15: 81-89.

Weis WI, Nelson WJ. 2006. Re-solving the cadherin-catenin-actin conundrum. J Biol Chem 281: 35593-35597.

West MJ, Gundersen HJ. 1990. Unbiased stereological estimation of the number of neurons in the human hippocampus. J Comp Neurol 296: $1-22$.

West MJ, Slomianka L, Gundersen HJ. 1991. Unbiased stereological estimation of the total number of neurons in the subdivisions of the rat hippocampus using the optical fractionator. Anat Rec 231: $482-497$.

Wickens JR, Reynolds JN, Hyland BI. 2003. Neural mechanisms of reward-related motor learning. Curr Opin Neurobiol 13: 685-690.

Yin HH, Mulcare SP, Hilario MR, Clouse E, Holloway T, Davis MI, Hansson AC, Lovinger DM, Costa RM. 2009. Dynamic reorganization of striatal circuits during the acquisition and consolidation of a skill. Nat Neurosci 12: 333-341.

Yu X, Malenka RC. 2003. $\beta$-catenin is critical for dendritic morphogenesis. Nat Neurosci 6: $1169-1177$.

Received April 16, 2012; accepted in revised form May 7, 2012. 


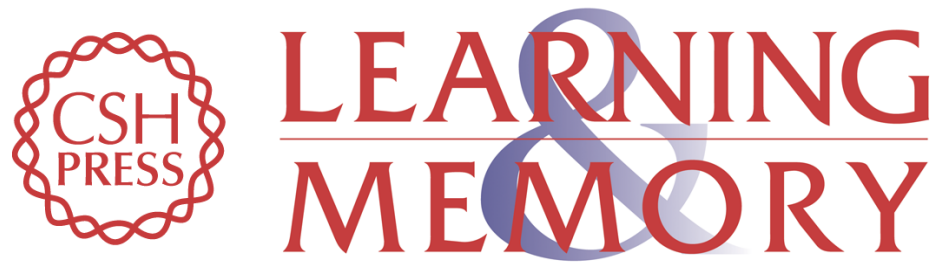

\section{Attenuated response to methamphetamine sensitization and deficits in motor learning and memory after selective deletion of $\beta$ -catenin in dopamine neurons}

Oscar Diaz-Ruiz, YaJun Zhang, Lufei Shan, et al.

Learn. Mem. 2012, 19:

Access the most recent version at doi:10.1101//m.026716.112

References This article cites 41 articles, 13 of which can be accessed free at: http://learnmem.cshlp.org/content/19/8/341.full.html\#ref-list-1

License

Email Alerting

Receive free email alerts when new articles cite this article - sign up in the box at the Service top right corner of the article or click here. 